\title{
Preparation and Characterization of Waterborne Polyurethane Crosslinked by Urea Bridges
}

\author{
Kalele Mulonda hercule (Corresponding author) \\ School of Chemical Engineering, Wuhan University of Technology \\ 205 Luoshi Road, Wuchang, Wuhan 430070, Hubei, China \\ Tel: 86-134-3713-6077Ｅ-mail: herculekalele@yahoo.fr \\ Zhu Yan \\ School of Chemical Engineering, Wuhan University of Technology \\ 205 Luoshi Road, Wuchang, Wuhan 430070, Hubei, China \\ Tel: 86-189-7151-9653Ｅ-mail: 59285910@qq.com \\ Mulenga Mbombo Christophe \\ Department of Chemistry, University of Kinshasa \\ Kinshasa IX, D. R. Congo \\ Tel: 243-99-826-0174 E-mail: c_mulenga@yahoo.fr
}

Received: December 28, 2010 Accepted: March 1, 2011 doi:10.5539/ijc.v3n2p88

\begin{abstract}
Waterborne polyurethanes are an interesting alternative to current solvent based polyurethanes used in many industries because of their high performance. In this study, waterborne polyurethane dispersion were prepared by polyaddition reaction using Polyethylene glycol (PEG $\left.\mathrm{M}_{\mathrm{w}} 2000\right)$ and isophorone diisocyanate (IPDI) in presence of dibutyltin dilaurate (DBTL) as catalyst. The urea bridges were created between waterborne polyurethane chains to improve rheological, thermal and mechanical properties by the incorporation of hexamethylene diisocyanate (HDI) as crosslinking agent. Several properties of crosslinked waterborne polyurethane were measured by particle size distribution, viscosity measurement, IR spectroscopy, differential scanning calorimetry (DSC), thermogravimetric analysis (TGA) and strength testing. This method improves the properties of waterborne polyurethane (WPD) in increasing the crosslinking density by forming strong network and hydrogen bonds between polyurethane chains.
\end{abstract}

Keywords: Waterborne polyurethane, Crosslinking agent, Urea bridge, Hydrogen bond

\section{Introduction}

Polyurethane (PU) is a most versatile polymer material, with a wide variety of physical and chemical properties that can be obtained from many commercially available and relatively cheap polyols, isocyanates and chain extender. PUs can be tailored to meet the highly diversified demands of modern technologies such as coatings, adhesives, fiber, foams, and thermoplastic elastomers. However, the environment considerations on emission of volatile organic compound (VOC) to the atmosphere is more and more restrictive and has forced many manufacturing polyurethane industries to devote a main part of their research and development on environment friendly product [Eun-Hee K., 2010; Ho T., 2007; Beck R. A., 1998].

Compared to their solvent counterpart, waterborne polyurethane dispersions can offer the following advantages: viscosity and flow properties independent of molecular weight, the absence of external emulsifiers, flexibility, good behaviour at low temperature and high strength, nontoxic, nonflammable, environmental safety, good adhesion and rheology characteristics that allows them to be use in wide application fields. Waterborne polyurethane present also drawbacks such as poor surface properties, deficiency in chemical resistance, poor wettability and limited thermal, mechanical and electrolytic stability caused principally by low crosslinking 
density [Karl-Ludwig N, 1977]. High levels of crosslinking cannot easily be introduced into waterborne polyurethane due to the problems of high viscosity prepolymers or poor coalescence of the formulated dispersion [Richard G. Coogan, 1997].

To overcome these problems many studies have been made in these last twenty years and a wide variety of curing crosslinkers are designed to improve the performance of aqueous polyurethane dispersions and acrylic latexes. These molecules introduced at the beginning of the formulation affect the viscosity of the polymer and can affect also the coalescence of particles. Another method contemplates the use of an external crosslinking agent, or the combination of polyol and aqueous dispersions of isocyanate [Zhu X., 2007].

This paper is devoted to improve the performance of waterborne polyurethane to be use in formulation of industrial paint, adhesive and coating by formation of urea bridges between chains by introducing hexamethylene diisocyanate in the formulation. The main advantage of using HDI, which have low molecular weight and low viscosity compared to other isocyanate, as internal crosslinker agent is that it can lead to the formation of dispersion with relatively small particle size and can't affect the viscosity of the waterborne polyurethane at the dispersion phase. Also lead to the formation of strong network by increasing the possibility of formation of hydrogen bonds in the medium.

\section{Experimental}

\subsection{Materials}

The polyurethane dispersions were prepared by reaction of an isocyanate, a macroglycol, an internal emulsifier and a chain extender. Polyethylene glycol (PEG; $\mathrm{M}_{\mathrm{w}}$ 2000) (supplied by Zhong Shan Mei Bang Nian Ji Co.,Ltd) was used as macroglycol, and it was dried at $110{ }^{\circ} \mathrm{C}$ under vacuum during 4 hours to remove residual water. The isophorone diisocyanate (IPDI; provided by Zhong Shan Mei Bang Nian Ji Co., Ltd) was used as diisocyanate. Dimethylolpropionic acid (DMPA; supplied by Guangzhou Guo Cai Pigment chemical industry) was dried at $100{ }^{\circ} \mathrm{C}$ during 2 hours in the oven before use as internal emulsifier agent. Dibutyltin dilaurate (DBTDL), N-methyl-2-pyrrolidone (NMP; provide by Sinopharm Chemical Reagent Co., Ltd) was used without further purification. Triethylamine (TEA; new pavillon chemical reagent, shanghai, china) was used as neutralization agent. Isopropyl alcohol (Tian Jin Guang Cheng Chemical Reagent Co., Ltd) was used as chain extender. Hexamethylene diisocyanate (HDI, supplied by Zhong Shan Mei Bang Nian Ji Co., Ltd) used as internal crosslinking agent. Double-distillated and deionized (DDI) water was used throughout.

\subsection{Synthesis of crosslinked waterborne polyurethane}

Polyurethane prepolymer was synthesized in bottom-rounded glass reactor equipped with a mechanical stirrer, a thermometer, a reflux condenser, a temperature controller. Polyethylene glycol (PEG $\left.\mathrm{M}_{\mathrm{w}} 2000 ; 0.01 \mathrm{~mole}, 20 \mathrm{~g}\right)$ and isophorone diisocyanate (IPDI; 0.03 mole, $6.67 \mathrm{~g}$ ) were charged into the reactor and the mixture was heated at $90{ }^{\circ} \mathrm{C}$ for 2 hours in presence of DBTDL as catalyst agent. Afterwards, calculated amount of DMPA (0.01 mole, $1.34 \mathrm{~g}$ ) dissolved in $10 \mathrm{ml}$ of NMP was added into the reactor and the reaction proceeded at the same temperature until the amount of residual NCO groups reached a theoretical value, as determined by the di-n-butylamine back-titration method, reduce the temperature of the reaction system to $50{ }^{\circ} \mathrm{C}$ and then add isopropyl alcohol $(0.04$ mole, $2.4 \mathrm{~g})$ and allow to react for one hour; then TEA $(0.01 \mathrm{~mol}, 1.01 \mathrm{~g})$ was added to neutralize the carboxylic acids moieties in the DMPA. HDI $(0.003 \mathrm{~mol}, 0.50 \mathrm{~g})$ was added at $80{ }^{\circ} \mathrm{C}$ to the mixture and then allowed reaction for half an hour. After that small amount of water was added. Finally double-distillated and deionized (DDI) water was drop wise added under vigorous stirring for 30 minutes then perform vacuum distillation [Jon Y. J., 2002; Suzana, 2010; Sankaraiah, 2007; Ji Y. K., 2004].

\subsection{Preparation of waterborne polyurethane films}

For some experiments, solid polyurethane films were used. They were prepared by placing about $100 \mathrm{ml}$ of waterborne polyurethane in a PTFE mould and allowing to dry at room temperature for a day. The polyurethane films obtained were annealed in an oven at $80^{\circ} \mathrm{C}$ for 24 hours to ensure the complete removal water in the film [Perez-Limin, 2005].

\subsection{Experimental techniques}

\subsubsection{Particle size distribution}

Particle size is an important parameter in deciding the industrial application of waterborne polyurethane dispersion. The average particle size distribution was measured using Zeta PALS provide by Brookhaven Instruments Corporation. The sample were diluted with deionized water to adjust solid content and directly placed in the cell. The measurements were carried out at $23^{\circ} \mathrm{C}$. 


\subsubsection{Viscosity}

The viscosity measurements were carried out at the temperature between 20 and $25{ }^{\circ} \mathrm{C}$ in the Ostwald viscometer and in three months interval time of preservation.

\subsection{3 $\mathrm{pH}$ measurement}

The $\mathrm{pH}$ values of the adhesives solutions were measured at $23{ }^{\circ} \mathrm{C}$ in $\mathrm{pH}-$-meter $\mathrm{HI} 8418$ of Hanna Instruments provided with a silver reference electrode.

\subsubsection{Infrared spectroscopy (FTIR)}

The chemistry of the polyurethane dispersion films was analyzed in a Nicolet 60 SXB infrared spectrophotometer provides with Fourier transform analysis (FTIR). The measurements were carried out by using the attenuated total reflectance (ATR) technique, and the Golden Gate single reflection diamond was used as prism. An incidence angle of the laser beam of $40^{\circ}$ was used and 500 scans were recorded and averaged.

\subsubsection{Differential scanning calorimetry (DSC)}

The thermal properties of the waterborne polyurethane films were measured in a differential scanning calorimeter Pyris I DSC provided by Perkin Elmer, equipped with a temperature program control. Around $10 \mathrm{mg}$ of waterborne polyurethane films were placed in aluminium pans and the experiments were carried out under nitrogen atmosphere by using a heating rate of $5{ }^{\circ} \mathrm{C} / \mathrm{min}$ from -75 to $75^{\circ} \mathrm{C}$.

\subsubsection{Thermogravimetric analysis (TGA)}

TGA experiments were performed in Pyris I Perkin Elmer thermal Analysis equipped with a temperature program control. $10 \mathrm{mg}$ of the polyurethane films were placed in aluminium crucibles and the experiments were carried out by heating from $45^{\circ} \mathrm{C}$ to $500{ }^{\circ} \mathrm{C}$, using a heating rate of $5{ }^{\circ} \mathrm{C} / \mathrm{min}$. Derivatives of weight loss versus temperature thermograms were obtained to better show the different decomposition processes.

\subsubsection{Tensile strength}

Tensile strength and elongation at the break of the films were measured on a tensile tester CMT 6503 provide by Shenzhen SANS test Machine Co., Ltd. China; with tensile rate of $5 \mathrm{~mm} / \mathrm{min}$ the size of the films was $30 \mathrm{~mm}$ length, $10 \mathrm{~mm}$ width. Three parallel measurements were carried out at room temperature and averaged.

\section{Results and discussion}

\subsection{Characterization of waterborne polyurethane solution}

The crosslinked waterborne polyurethane produced dispersion with $36 \%$ solid content and $\mathrm{pH}$ value around 7.8

The table 1 shows the particle size distribution of the waterborne polyurethane dispersion crosslinked by HDI in function of stirring rate during the synthesis process and over time. Crosslinked waterborne polyurethane shows a narrow particle size [Mohammad B., 2005]. Through this table we can found that the means particle size decrease with the increasing of stirring speed during the synthesis and slightly increase during the preservation that could due to the excessive viscosity during the dispersion step and the increase of this one with the preservation time.

In fact, through table 2 we can observe the thixotropy in our sample (the viscosity increases by increasing time of preservation) and also the viscosity decreases with increasing temperature. The existence of thixotropy in the crosslinked waterborne polyurethane can mainly due to the creation of hydrogen bonds between polyurethane chains [Samy A., 2009; Werner J. B., 1996].

\subsection{Characterization of solid waterborne polyurethane films}

The chemistry of solid crosslinked waterborne polyurethane films was analyzed by FTIR spectroscopy. The assignments of the main IR bands of the aqueous polyurethane dispersion are given in table 3 [Kastner U, 2001].

The figure 2 shows the ATR-IR spectra of the solid crosslinked waterborne polyurethane film and non crosslinked polyurethane film. Furthermore, the crosslinking reaction of polyurethane dispersion produces an increase in the relative intensity of the urea band with respect to that of $\mathrm{C}=\mathrm{O}$ of urea and urethane groups at 1732 $\mathrm{cm}^{-1}$. The HDI produced an increase in the relative intensity of N-H stretching band at $3370 \mathrm{~cm}^{-1}$ and the stretching $\mathrm{CN}$ and $\mathrm{N}-\mathrm{H}$ band at $1532 \mathrm{~cm}^{-1}$, also see an increase in relative intensity of C-H stretching band at $2954 \mathrm{~cm}^{-1}$. Moreover, the ATR-IR spectrum shows the characteristics C-O-C stretching bands of the macroglycol at 1240, 1173, 1142, 1079 and $955 \mathrm{~cm}^{-1}$. 
The ATR-IR spectrum of the waterborne polyurethane dispersion also shows a slight shift in the value of the characteristic peaks and this is probably due to the formation of hydrogen bonds [Elana O., 2009] between chains contributing to the strengthening of crosslinking of waterborne polyurethane dispersion.

The thermal properties of the crosslinked waterborne polyurethane were studied by DSC. The figure 3 shows the DSC thermograms in the temperature range of -75 to $75^{\circ} \mathrm{C}$ of the waterborne polyurethane films. As we know, in DSC experiments, the glass transition temperature is generally taken as the inflection point of the specific heat increment at the glass-rubber transition. The DSC thermograms shows the $\mathrm{T}_{\mathrm{g}}$ of the soft segments located at low temperature, followed by the crystallization process of the soft segment (external peak) [Zoran, 2005].

Crosslinked waterborne polyurethane shows an increase in the $\mathrm{T}_{\mathrm{g}}$ value $\left(-43.163{ }^{\circ} \mathrm{C}\right)$ compared to the non-crosslinked polyurethane $\left(-46.752{ }^{\circ} \mathrm{C}\right)$ that is ascribed to the formation of strong network between polyurethane chains [Glass J. E, 1999]. The crystallization temperature $\mathrm{T}_{\mathrm{c}}$ around $-13{ }^{\circ} \mathrm{C}$. This indicates that the crosslinked mechanism does not disturb the degree of phase separation between the soft and hard segments in the waterborne polyurethane.

The thermal resistance of the crosslinked waterborne polyurethane films was analyzed by TGA, the weight loss versus temperature is shown in the figure 4 . We can found that the crosslinking produces a slight delay in the thermal degradation of the waterborne polyurethane what is ascribed to the formation of a network and the interaction between polyurethane chains. Also the crosslinked polyurethane shows small increase in the decomposition temperature (table 5) indicating an improvement in stability degradation of the polyurethane.

Finally the mechanical properties of the crosslinked waterborne polyurethane as well as the WPD films were investigated by tensile testing at room temperature. Table 6 shows the effect of crosslinking on the mechanical properties.

From the results, we can see that the crosslinking network has a profound effect on the mechanical properties. The tensile strength increases from 8.65 to $16.3 \mathrm{MPa}$ and the Youngs'modulus also increases significantly from 49.36 to $82.31 \mathrm{MPa}$.

These results suggested that crosslinking could lead to more physical entanglement with the waterborne polyurethane adhesives and contribute to their ultimate strength [Ming Z., 2005]. The improvement in the tensile strength can probably be explained from enhancement in crosslinking density and the strong hydrogen bonding interaction between waterborne polyurethane chains.

\section{Conclusion}

Waterborne polyurethane can be crosslinked with variety of crosslinker agent to improve the thermal and mechanical properties. The crosslinking method by introduction of urea bridge (bond) between the chains has the advantage of not involving an external crosslinking agent that may increase the viscosity of the dispersion but it is through the use of a low molecular weight diisocyanate.

This crosslinking method produced an improvement in the rheological, thermal and mechanical properties of waterborne polyurethane dispersions by the formation of a strong network between polyurethane chains. In the end, the creation of urea bridges between polyurethane dispersion chains was confirmed by the analyzing of the FTIR spectrum on which there is an increase in the intensity of characteristic bands of urethane and urea.

Furthermore the crosslinking by urea bridges leads to the formation of intermolecular hydrogen bonds (shift in the value of the characteristic peaks) that contributing effectively to the mechanism of crosslinking.

\section{References}

Beck R. A. (1998). Truss R.W. Wear., 218:145-152.

Elana O., Franscica A., Ana M. T., Cesar O., Jose M. (2009). International Journal of Adhesion and Adhesives, 29:309-318.

Eun-Hee K., Woo-Rom L., Sang-Wong M. (2010). Progress Organic Coating, 67:102-106.

Glass J. E. (1999). Advances in Colloid Inter. Sciences, 79:123-148.

Ho T., Moon K. J., Byung K. K., Kwang H. K. (2007). Colloids and Surf. A: Physicochem. Eng Aspect., 302:559-567.

Ji Y. K., Eun Y. K., Han D. K. (2004). Macromolecular Research, 12 :3 :303-310.

Jon Y. J., Young K. J., In W. C., Jung H. K. (2002). Colloid and Surf. A: Physicochem Eng Aspect, 196:135-143.

Karl-Ludwig N. (1997). Progress in Organic Coating, 32:131-136. 
Kastner U. (2001). Colloids and Surf. A: Physicochem. Eng. Aspect., 183-5.

Lapprand, A. (2005). Thèse de doctorat, INSA de Lyon, 228.

Ming Z., Lina Z., John F.K. (2005). Carbohydrate Polymer, 60:399-409.

Mohammad B., Babak K., Mehdi B. (2005). European Polymer Journal, 41:619-626.

Perez-Limin ana MA, Ara-Aıs F, Torro'-Palau AM, Orgile-Barcelo' AC, Martınez JM. (2005). International Journal of Adhesions and Adhesives, 25:507-17.

Richard G. Coogan. (1997). Progress in Organic Coating, 32:51-63.

Rosthauser J. W., Nachtkamp K. (1987). Advances in Urethane Science Technology, 10 :121-162.

Samy A., Madbouly, Joshua U., Otaigbe. (2009). Progess Polymer Science, 34:12:1283-1332.

Sankaraiah S., Jun Y. L., Jung H. K., In W. C. (2007). Composite Science and Technology, 67:1566-1573.

Suzana M. C., Ivan S. R., Dragan M. D., Jakov V. S. (2010). Progress in Organic Coating, 67:274-280.

Werner J. B., Vslentino J. T. (1996). Progress in Organic Coating, 27:1-15.

Zhu X., Zhang Q., Liu L., Kong X., Feng S. (2007). Progress in Organic Coating, 59:324-330.

Zoran S. P. (2005). In Handbook of Polymer Synthesis (2th edition), Marcel Dekker, New York. Chapter 8.

Table 1. Particle size distribution in function of stirring rate

\begin{tabular}{|c|c|c|c|c|c|c|}
\hline \multirow{2}{*}{ Time } & \multicolumn{6}{|c|}{ Particle size $(\mathrm{nm})$} \\
\cline { 2 - 7 } & $1000(\mathrm{rpm})$ & $1200(\mathrm{rpm})$ & $1400(\mathrm{rpm})$ & $1600(\mathrm{rpm})$ & $1800(\mathrm{rpm})$ & $2000(\mathrm{rpm})$ \\
\hline Day 1 & 245.6 & 221.6 & 200 & 166.5 & 144.5 & 141.3 \\
\hline Day 31 & 281.9 & 224.8 & 209.2 & 178.8 & 166.0 & 147.1 \\
\hline Day 62 & 286.8 & 258.5 & 212.6 & 179.5 & 171.3 & 151.4 \\
\hline
\end{tabular}

Table 2. Viscosity in function of preservation time

\begin{tabular}{|l|l|l|l|l|l|l|}
\hline \multirow{2}{*}{ Time } & \multicolumn{7}{|c|}{ Viscosity $(\mathrm{mPa} \mathrm{s})$} \\
\cline { 2 - 7 } & $20{ }^{\circ} \mathrm{C}$ & $21{ }^{\circ} \mathrm{C}$ & $22{ }^{\circ} \mathrm{C}$ & $23{ }^{\circ} \mathrm{C}$ & $24{ }^{\circ} \mathrm{C}$ & $25^{\circ} \mathrm{C}$ \\
\hline Day 1 & 286.27 & 257.55 & 226.95 & 190.25 & 158.25 & 151.2 \\
\hline Day 7 & 291.15 & 259.38 & 228.61 & 187.243 & 158.54 & 149.672 \\
\hline Day 31 & 292.385 & 261.67 & 229.173 & 194.916 & 161.415 & 159.28 \\
\hline Day 62 & 295.729 & 263.432 & 231.387 & 213.821 & 177.693 & 164.387 \\
\hline Day 93 & 300.115 & 270.57 & 239.654 & 218.843 & 182.631 & 184.862 \\
\hline
\end{tabular}

Table 3. Characteristic IR bands of the polyurethane

\begin{tabular}{|l|l|}
\hline Wavelength $\left(\mathrm{cm}^{-1}\right)$ & Assignment \\
\hline 3370 & st N-H (associated) \\
\hline 2954 & $\mathrm{C}-\mathrm{H}\left(\mathrm{CH}_{2}, \mathrm{CH}_{3}\right)$ \\
\hline 1735 & $\mathrm{C}=\mathrm{O}($ ester and urethane $)$ \\
\hline 1532 & st C-N $+\mathrm{N}-\mathrm{H}$ \\
\hline 1460 & $\delta \mathrm{CH}_{2}, \mathrm{CH}_{3}$ \\
\hline 1418 & $\delta$ asym $\mathrm{CH}_{3}$ \\
\hline 1387 & $\delta_{\text {oop }} \mathrm{C}-\mathrm{H}\left(\mathrm{CH}_{2}\right)$ \\
\hline 1240 & st asym N-CO-O $+(\mathrm{C}-\mathrm{O}-\mathrm{C})$ \\
\hline 1173 & st C-O-C \\
\hline 1079 & st sy N-CO-O + st C-O-C \\
\hline 955 & $\mathrm{C}-\mathrm{O}-\mathrm{C}$ \\
\hline 774 & $\delta_{\text {oop }} \mathrm{C}=\mathrm{C}-\mathrm{H}$ \\
\hline
\end{tabular}

st: stretching, $\delta$ : bending, sy: symmetric, asym: non-symmetric, $\delta_{\text {oop }}$ : bending out the plane 
Table 4. Some values obtained from DSC thermograms of the crosslinked polyurethane

\begin{tabular}{|l|l|l|l|l|}
\hline Polyurethane & $\mathrm{Tg}\left({ }^{\circ} \mathrm{C}\right)$ & $\Delta \mathrm{Hc}(\mathrm{J} / \mathrm{g})$ & $\mathrm{Tc}\left({ }^{\circ} \mathrm{C}\right)$ & $\Delta \mathrm{Cp} \mathrm{J} / \mathrm{g}{ }^{\circ} \mathrm{C}$ \\
\hline WPD & -46.752 & 36 & -15 & 0.919 \\
\hline Crosslinked WPD & -43.163 & 39 & -13 & 1.011 \\
\hline
\end{tabular}

Table 5. Decomposition temperature and weight loss percentage

\begin{tabular}{|l|l|l|l|l|l|l|}
\hline \multirow{2}{*}{ Sample } & \multicolumn{2}{l|}{ First decomposition } & \multicolumn{2}{l|}{ Second decomposition } & \multicolumn{2}{l|}{ Third decomposition } \\
\cline { 2 - 8 } & $\mathrm{T}\left({ }^{\circ} \mathrm{C}\right)$ & Weight loss $(\%)$ & $\mathrm{T}\left({ }^{\circ} \mathrm{C}\right)$ & Weight loss $(\%)$ & $\mathrm{T}\left({ }^{\circ} \mathrm{C}\right)$ & Weight loss $(\%)$ \\
\hline WPD & 200 & 4.175 & 340 & 46.011 & 480 & 93.984 \\
\hline Crosslinked WPD & 200 & 0.858 & 340 & 42.315 & 480 & 88.278 \\
\hline
\end{tabular}

Table 6. Mechanical properties of thickened waterborne polyurethane obtained from tensile test. $(\sigma)$ Tensile strength; (E) Youngs'Modulus; $\left(\varepsilon_{\mathrm{p}}\right)$ elongation at break

\begin{tabular}{|l|l|l|l|}
\hline Sample & $\sigma(\mathrm{MPa})$ & $\mathrm{E}(\mathrm{MPa})$ & $\varepsilon_{\mathrm{p}}(\%)$ \\
\hline WPD & $8.65 \pm 0.5$ & $49.36 \pm 1$ & 4.09 \\
\hline Crosslinked WPD & $16.3 \pm 0.5$ & $82.31 \pm 1.6$ & 6.85 \\
\hline
\end{tabular}



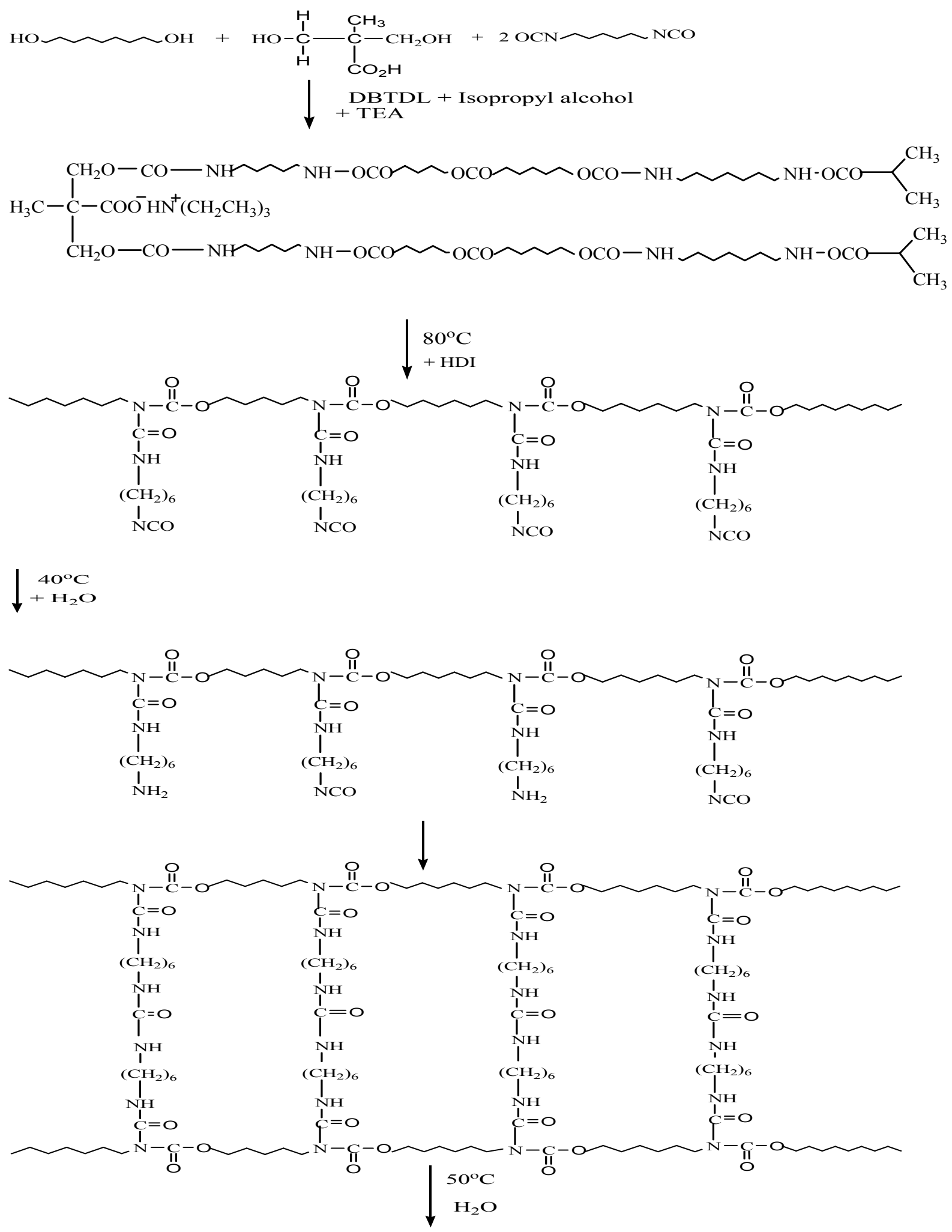

Aqueous polyurethane dispersion

Figure 1. Scheme of the crosslinking reaction by Hexamethylene diisocyanate [Rosthauser, 1987; Lapprand, 2005] 


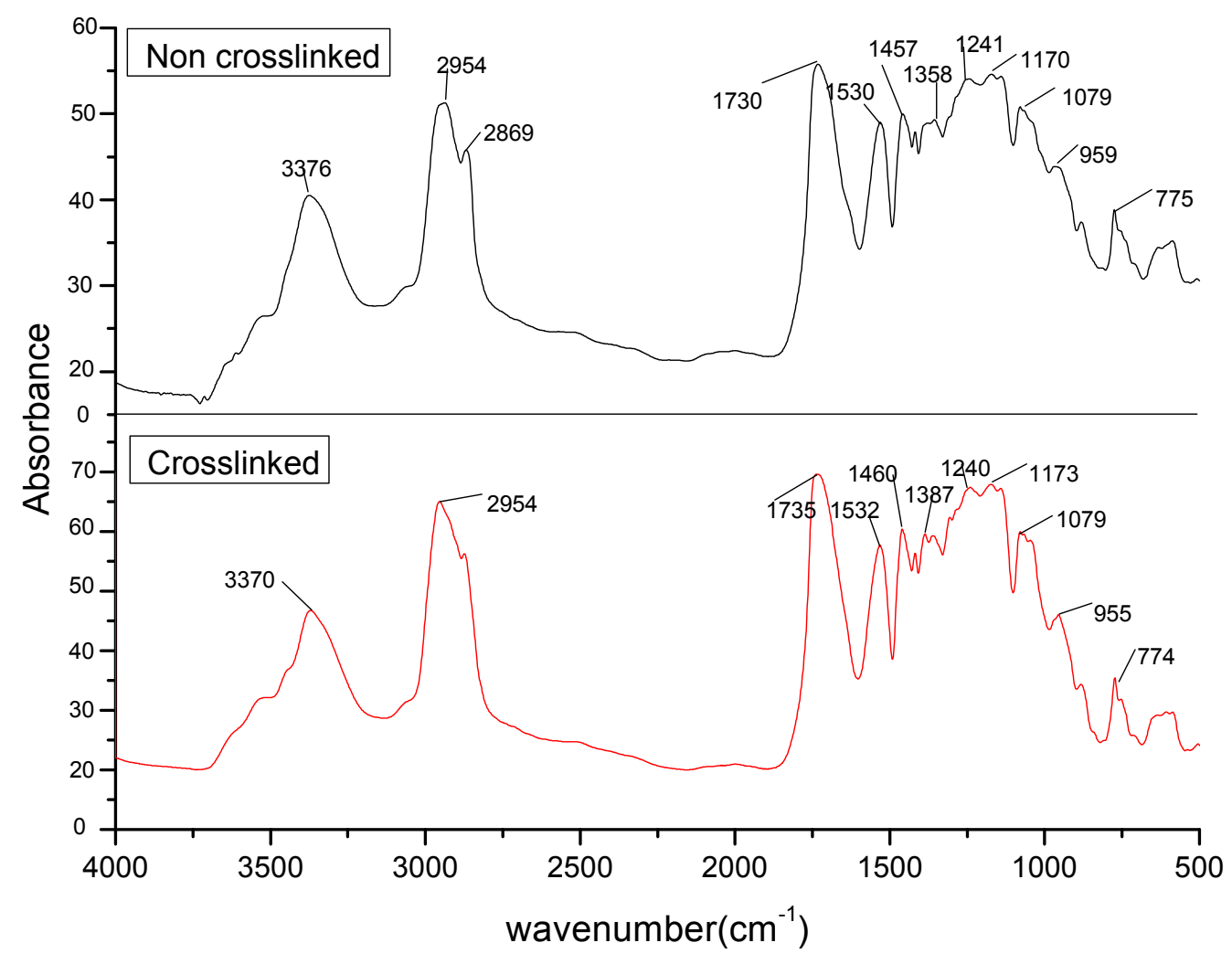

Figure 2. ATR-IR spectra of the crosslinked polyurethane

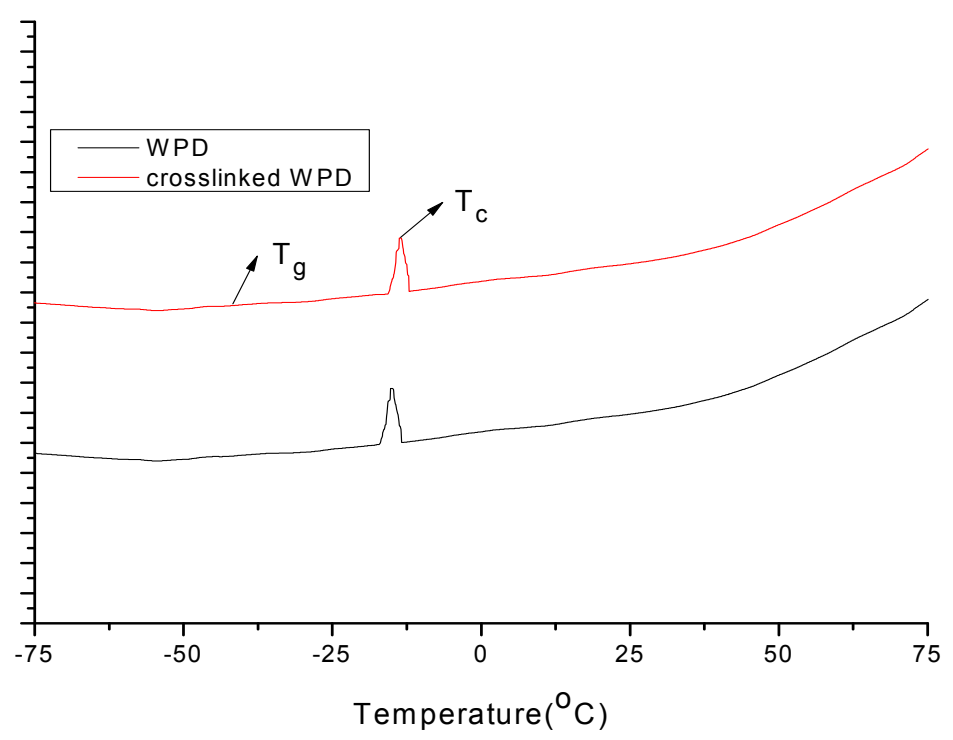

Figure 3. DSC curves of waterborne polyurethane 


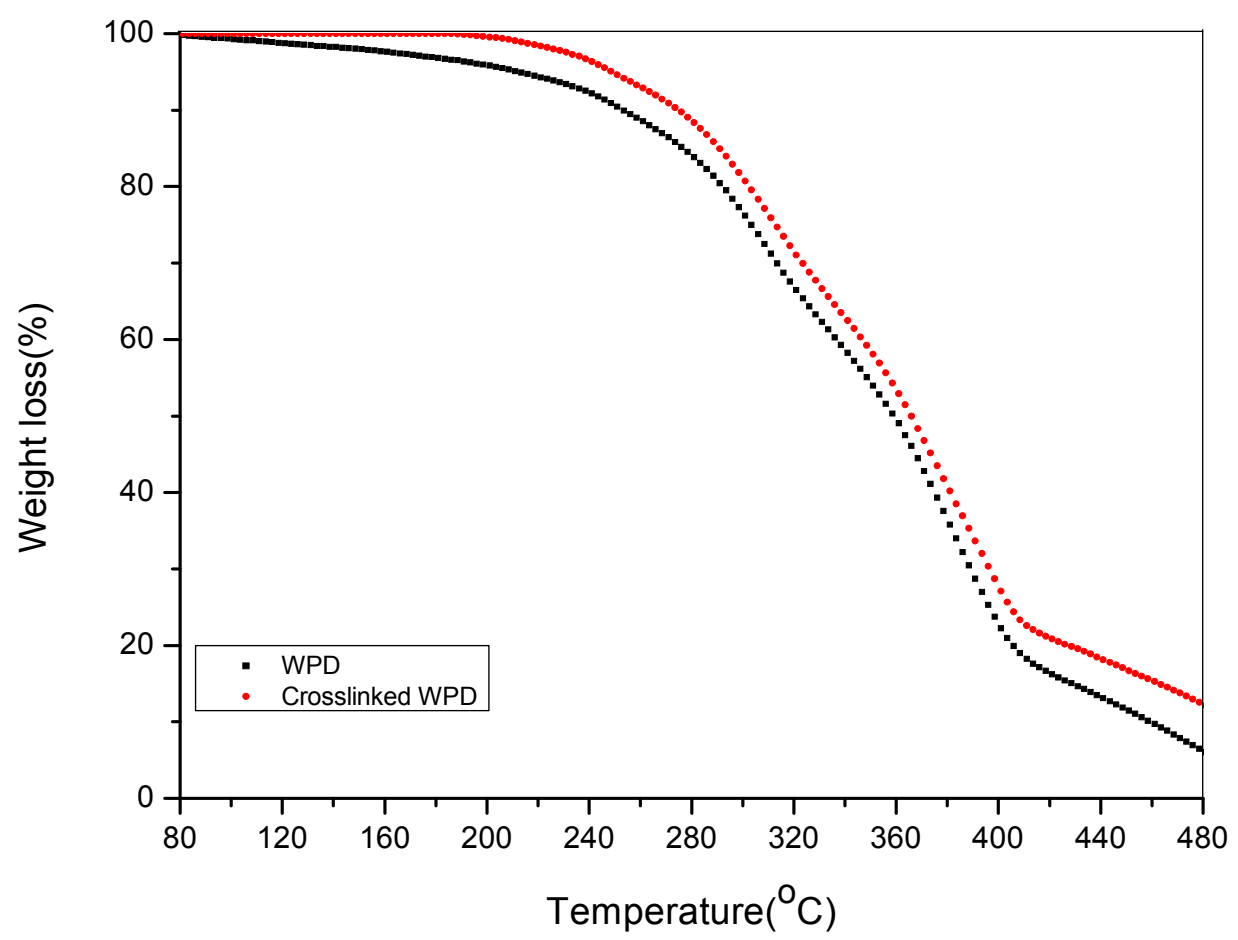

Figure 4. TGA curves of waterborne polyurethane 